\title{
Amino Acid Sequences of Lactoferrin from Red Deer (Cervus elaphus) Milk and Antimicrobial Activity of Its Derived Peptides Lactoferricin and Lactoferrampin
}

\author{
Ye Wang ${ }^{1, *}$, James D. Morton ${ }^{1}(0)$, Alaa EL-Din A. Bekhit ${ }^{2} \oplus$, Alan Carne $^{3}$ and Susan L. Mason ${ }^{1}$ \\ 1 Department of Wine, Food and Molecular Biosciences, Lincoln University, P.O. Box 84, Lincoln 7674, \\ New Zealand; james.morton@lincoln.ac.nz (J.D.M.); sue.mason@lincoln.ac.nz (S.L.M.) \\ 2 Department of Food Science, University of Otago, P.O. Box 56, Dunedin 9054, New Zealand; \\ aladin.bekhit@otago.ac.nz \\ 3 Department of Biochemistry, University of Otago, P.O. Box 56, Dunedin 9054, New Zealand; \\ alan.carne@otago.ac.nz \\ * Correspondence: yewang1986@gmail.com
}

check for updates

Citation: Wang, Y.; Morton, J.D.; Bekhit, A.E.-D.A.; Carne, A.;

Mason, S.L. Amino Acid Sequences of Lactoferrin from Red Deer (Cervus elaphus) Milk and Antimicrobial Activity of Its Derived Peptides Lactoferricin and Lactoferrampin. Foods 2021, 10, 1305. https://doi.org/ $10.3390 /$ foods10061305

Academic Editor: Golfo Moatsou

Received: 26 April 2021

Accepted: 1 June 2021

Published: 7 June 2021

Publisher's Note: MDPI stays neutral with regard to jurisdictional claims in published maps and institutional affiliations.

Copyright: (c) 2021 by the authors. Licensee MDPI, Basel, Switzerland. This article is an open access article distributed under the terms and conditions of the Creative Commons Attribution (CC BY) license (https:// creativecommons.org/licenses/by/ $4.0 /)$.

\begin{abstract}
Although the bioactivities of bovine lactoferrin have been extensively investigated, little is known about deer milk lactoferrin bioactivity and its amino acid sequence. This research investigated the amino acid sequence of deer lactoferrin and the antimicrobial activities of two lactoferrinencrypted peptides; lactoferricin (Lfcin) and lactoferrampin (Lfampin). Deer lactoferrin was found to have a molecular weight of $77.1 \mathrm{kDa}$ and an isoelectric point of 7.99 , which are similar to that of bovine lactoferrin, $78 \mathrm{kDa}$ and pI 7.9. Deer lactoferrin contains 707 amino acids, one amino acid less than bovine lactoferrin, and has $92 \%$ homology with bovine lactoferrin. Deer lactoferricin exhibited strong antimicrobial activity against E. coli American Type Culture Collection (ATCC) 25922 and L. acidophilus ATCC 4356. The antimicrobial activities of deer and bovine Lfcin and Lfampin were compared. Based on MIC, deer Lfcin was found to be a more effective inhibitor of L. acidophilus ATCC 4356 than bovine Lfcin, but bovine Lfcin and Lfampin were more effective against E. coli ATCC 25922 than deer Lfcin and Lfampin. The deer Lfcin sequence differed at seven amino acids from bovine Lfcin and this decreased the net positive charge and increased the hydrophobicity. Deer Lfampin contained two differences in amino acid sequence compared to bovine Lfampin which decreased the net positive charge. These amino acid sequence differences likely account for differences in antibacterial activity. Positive charge and hydrophobic residues provide the amphipathic character of these helical peptides, and are considered important for binding of antimicrobial peptides. In silico modelling of deer Lfcin indicated an identical $\alpha$-helical structure compared to bovine Lfcin.
\end{abstract}

Keywords: deer lactoferrin amino acids; deer lactoferricin; deer lactoferrampin; antibacterial activity

\section{Introduction}

The extended use of antibiotics has led to antibiotic resistance which threatens global health and food security. Antimicrobial peptides have potential as alternatives to antibiotics. Compared with traditional antibiotics, a typical antimicrobial peptide can have a higher isoelectric point, better thermal stability, broader-spectrum antimicrobial properties, and can be more amenable to preparation in a sterile form [1]. It has been suggested that antimicrobial peptides should not cause widespread resistance, due to their preferential attack on bacterial cell membranes [2]. Dairy products are an important source of antimicrobial peptides [3]. There has been a dramatic increase in the farming of red deer recently and emergence of deer milk dairying, hence deer milk could provide a potential alternative source of antimicrobial peptides $[4,5]$.

The whey protein lactoferrin (Lf), an iron-binding glycoprotein of the transferrin family, exhibits antimicrobial properties in its intact form. Lf from bovine is the most 
studied among all species [6]. Bovine Lf is comprised of 708 amino acids with a molecular weight of $78 \mathrm{Da}$ [7]. A number of mechanisms have been suggested for the antimicrobial activity of Lf, including iron deprivation from bacteria [8], direct interaction with pathogenic microorganisms causing cell lysis [9], and prevention of the interaction between bacteria and host cells [10]. Several antimicrobial peptides are reported to be encrypted in bovine Lf. The most well-known are the two peptides, lactoferricin (Lfcin, 17-41) and lactoferrampin (Lfampin, 265-284). These two peptides are reported to exhibit substantial broad spectrum activity against bacteria, yeast, fungi and parasites [11]. Bovine Lfcin derived from the N-terminal domain of Lf (17-41) (FKCRRWQWRMKKLGAPSITCVRRAF) [12] can be generated by in vitro digestion with pepsin at $\mathrm{pH} 3,37^{\circ} \mathrm{C}$ for $4 \mathrm{~h}$, and was found to display broad spectrum activity against bacteria, yeast, fungi, and parasites [13]. Bovine Lfampin (268-284) (WKLLSKAQEKFGKMKSR), is derived from the C-terminal domain of Lf [12]. Bovine Lfampin has been chemically synthesized and demonstrated to exhibit candidacidal activity, and antibacterial activity against Bacillus subtilis, Escherichia coli, and Pseudomonas aeruginosa [14].

No studies to date have been carried out investigating the amino acid sequence of deer Lf. Analysis of the primary structure of antimicrobial peptides encrypted in proteins such as Lf can help in understanding the mechanisms of their antimicrobial activities. Comparison of the similarities and differences between deer Lf and bovine Lf may provide insights into the antimicrobial activity of deer Lf and its peptides, as well as any potential advantage of deer milk as an alternative milk product. The objectives of the present study were to investigate the amino acid sequence of Lfcin and Lfampin in deer milk Lf, compared to that of bovine Lf, and the antimicrobial properties of the peptides.

\section{Materials and Methods}

\subsection{Materials}

Ion exchange chromatography materials were obtained from GE Healthcare (now Cytiva), Uppsala, Sweden. All chemicals for sodium dodecyl sulphate-polyacrylamide gel electrophoresis (SDS-PAGE) were obtained from Bio-Rad Laboratories, Irvine, CA, USA, unless otherwise stated. Bacterial strains used in antibacterial activity assays (Escherichia coli ATCC 25922, Staphylococcus aureus ATCC 25923, and L. acidophilus ATCC 4356) were from ESR (Christchurch, Canterbury, New Zealand). A LIVE/DEAD BaclightTM bacterial viability kit (L7007) was from Molecular Probes, Eugene, OR, USA, with detection using a fluorescence microscope (Nikon Eclipse 50i, Tokyo, Japan), were used for assay of bacterial cell viability. Commercial bovine Lf was used for in vitro digestion and antibacterial activity assay.

\subsection{Purification of Deer Lactoferrin by Fast Protein Liquid Chromatography}

Lf was enriched from deer milk using a sequential ion exchange chromatography method [15]. Deer milk sweet whey was prepared by adding $1 \mathrm{~mL}$ renin solution (Renco, Eltham, New Zealand) per litre of deer milk, incubating at $37^{\circ} \mathrm{C}, 1 \mathrm{~h}$, and the clarified sweet whey fraction was obtained by centrifuging at $10,000 \times g, 15 \mathrm{~min}$. Deer milk whey was filtered (DVPP, $0.45 \mu \mathrm{m}$, Durapore ${ }^{\circledR}$, Millipore, Carrigtwohill, Ireland) and the $\mathrm{pH}$ was adjusted to 3.8 with $1 \mathrm{M} \mathrm{HCl}$ and initially subjected to anion exchange chromatography using two $\times 5 \mathrm{~mL}$ HiTrap Q-FF cartridges (GE Healthcare) linked in series, equilibrated with $20 \mathrm{mM}$ sodium citrate, $\mathrm{pH} 3.8$, containing $40 \mathrm{mM} \mathrm{NaCl}$, on a FPLC (BioLogic DuoFlow, GE Healthcare). The unbound protein fraction was collected and adjusted to $\mathrm{pH} 7.0$ and loaded onto a $5 \mathrm{~mL}$ HiTrap SP-FF cartridge (GE Healthcare), equilibrated in $20 \mathrm{mM}$ sodium dihydrogen phosphate, $\mathrm{pH}$ 7.0. Bound proteins were eluted with stepwise increase in ionic strength using sodium dihydrogen phosphate, $\mathrm{pH} 7.0$, containing (i) $0.1 \mathrm{M} \mathrm{NaCl}$, (ii) $0.4 \mathrm{M} \mathrm{NaCl}$, and (iii) $1.0 \mathrm{M} \mathrm{NaCl}$. Protein containing fractions were collected, concentrated, and desalted using Vivaspin ${ }^{\circledR} 20,10 \mathrm{kDa}$ MWCO spin filter units (GE Healthcare). Fractions were analyzed by SDS-PAGE, to confirm that the Lf eluted in the $1.0 \mathrm{M} \mathrm{NaCl}$ step. 


\subsection{SDS-PAGE}

Deer Lf was analyzed by SDS-PAGE on an in-house made $12 \%$ acrylamide gel run in a Bio-Rad mini-gel electrophoresis system according to a standard protocol [16]. The gels were made with resolving gel 1.5 M Tris ( $\mathrm{pH} 8.8)$, stacking gel $0.5 \mathrm{M}$ Tris $(\mathrm{pH} 6.8)$, $30 \%(w / v)$ acrylamide/bis-acrylamide (37.5:1, 2.6\% C), 10\% (w/v) SDS solution, using $10 \%$ $(w / v)$ ammonium persulfate and TEMED as catalysts. Protein samples were diluted with sample buffer, which contained $0.23 \mathrm{M}$ Tris ( $\mathrm{pH} 6.8), 8 \%$ SDS, $40 \%(v / v)$ glycerol, $0.08 \%$ $(w / v)$ bromophenol blue and $4 \%(v / v)$ mercaptoethanol, with heating at $72^{\circ} \mathrm{C}$ for $10 \mathrm{~min}$ prior to loading on the gel. BioRad Precision Plus Protein ${ }^{\mathrm{TM}}$ standard (\#1610373) was used as a molecular weight marker. Electrophoresis was performed at a constant voltage of $120 \mathrm{~V}$ for $90 \mathrm{~min}$. After electrophoresis, the gel was fixed in 50\% $(\mathrm{v} / \mathrm{v})$ methanol and $7 \%$ $(v / v)$ acetic acid for $15 \mathrm{~min}$ and then washed $3 \times 5 \mathrm{~min}$ with reverse osmosis grade water and then stained with GelCode ${ }^{\mathrm{TM}}$ Blue (Thermo Scientific ${ }^{\mathrm{TM}}$, \#24590, USA), according to the supplier's instructions. Stained SDS gels were scanned using a CS90000F Mark II scanner (Canon, Auckland, New Zealand).

\subsection{Deer Lf Amino Acid Sequence Analysis}

The deer Lf band excised from a stained SDS-PAGE was subjected to an in-gel digestion process, in which the gel was diced into small pieces and subjected to in-gel digestion with sequencing grade modified trypsin (Promega, Madison, WI, USA) based on a published method [17]. The extracted tryptic peptides were dried in a Savant Speed Vac Plus (Savant, Hyannis, MA, USA), and then redissolved in 20-50 $\mu \mathrm{L}$ of $5 \%(v / v)$ acetonitrile, $0.2 \%(v / v)$ formic acid in Type $1 \mathrm{MQ}$-water, and aliquots were injected onto an Ultimate 3000 nano-flow uHPLC-System (Dionex, Sunnyville, CA, USA) that was in-line coupled to the nano-spray source of an LTQ-Orbitrap XL hybrid mass spectrometer (Thermo Scientific, San Jose, CA, USA). Peptides were separated on an in-house packed emitter-tip column (75 $\mu \mathrm{m}$ ID PicoTip fused silica tubing of length 8-9 cm (New Objective, Woburn, MA, USA), packed with C-18 resin, and using $0.2 \%(v / v)$ formic acid in MQ-water (buffer A) and $0.2 \%(v / v)$ formic acid in acetonitrile (buffer $\mathrm{B})$, with a gradient developed from $5 \%(v / v)$ acetonitrile, $0.2 \%[v / v]$ formic acid to $99 \%[v / v]$ acetonitrile, $0.2 \%[v / v]$ formic acid in water at a flow rate of $400 \mu \mathrm{L} / \mathrm{min}$ [18].

A typical instrument setting for the LTQ-Orbitrap was full MS in a mass range between $m / z$ 400-2000, performed in the Orbitrap mass analyzer with a resolution of 60,000 and an AGC target of 5e5. Preview mode for FTMS master scan was enabled to generate precursor mass lists. The highest 7 signals were selected for CID (collision induced dissociation)MS/MS in the LTQ ion trap at a normalized collision energy of 35\% using an AGC target of $1 \mathrm{e} 6$ and one micro scan. Dynamic exclusion was enabled with 2 repeat counts during $90 \mathrm{sec}$ and an exclusion period of $120 \mathrm{sec}$. Exclusion mass width was set to 0.01. After the initial LC-MS analysis of the sample from SDS-PAGE, the LC-MS/MS was repeated twice with different LC gradients ( $45 \mathrm{~min}$ method $=5-25 \%$ B over $17 \mathrm{~min}, 25-40 \%$ B over $4 \mathrm{~min}, 40-99 \%$ B over $4 \mathrm{~min}$ ) and (60 min method $=5-25 \%$ B over $27 \mathrm{~min}, 25-40 \%$ B over $8 \mathrm{~min}, 40-99 \%$ B over $4 \mathrm{~min}$ ), to optimize peptide fractionation and maximize the dynamic range of peptide MS analysis by allowing for bias in hydrophobicity and complexity of the peptides in multiple fractions.

MS/MS data were searched against a deer protein sequence database that was generated from a deer transcriptome analysis undertaken in-house in the Department of Biochemistry, University of Otago. The Lf sequences were interrogated with the MS/MS data obtained using the Mascot search engine [19]. The search for the data obtained from the in-gel digest of the deer Lf protein band was set up for full tryptic peptides and a maximum 3 missed cleavage sites. The search for the data obtained from peptide fractions from RP-HPLC was set up for non-tryptic peptides. Deamidation, oxidized methionine, and carboxyamidomethyl cysteine, were included as variable modifications for in-gel digest samples, and deamidation and oxidized methionine were included for in-solution HPLC samples, with a fragment mass error of $0.4 \mathrm{Da}$ and a precursor mass tolerance of $75 \mathrm{ppm}$. 
SwissProt was used to search for sequence coverage of deer Lf for tryptic, chymotryptic and semi-chymotryptic peptides.

\subsection{Three-Dimensional Structures of Deer Lfcin and Lfampin In Silico Analysis}

3-D structures of the peptides Lfcin and Lfampin were simulated in PyMOL (Schrödinger Inc., New York, NY, USA). Based on the amino acid sequences of deer Lf, 3-D structures of deer Lfcin and Lfampin were automatically modelled in minimized (optimized) energy form in PyMOL. The full amino acid sequences and the 3-D structure of bovine Lf were obtained from the Protein Data Bank (PDB ID: 1BLF) [12].

\subsection{Antibacterial Activity Assay for Deer Lfcin and Lfampin}

Synthetic deer and bovine Lfcin and Lfampin were custom made by GL Biochem Ltd. (Shanghai, China), according to their amino acid sequences. The commercial synthetic peptides were desalted and of high purity $(>98 \%)$ and verified using HPLC and MS. The antibacterial activity assay for the synthetic peptides and controls was performed according to the European Committee for Antimicrobial Susceptibility Testing Protocol [20]. Bacteria in broth were serially diluted with broth to $5 \times 10^{5}$ cells $/ \mathrm{mL}$ for E. coli and S. aureus, and at $1.5 \times 10^{8}$ cells $/ \mathrm{mL}$ for L. acidophilus. This was because L. acidophilus at a lower cell density $\left(10^{5}\right.$ cells $\left./ \mathrm{mL}\right)$ could not achieve experimentally a good growth curve. A $100 \mu \mathrm{L}$ aliquot of bacteria in broth was transferred into each well of a 96-well plate and mixed with $100 \mu \mathrm{L}$ peptide stock at different concentrations $(15-960 \mu \mathrm{g} / \mathrm{mL})$ prepared in broth. The OD600 of the cells in the 96-well plate was obtained hourly using a plate reader during $24 / 48 \mathrm{~h}$ incubation at $37^{\circ} \mathrm{C}$. Minimum inhibitory concentration (MIC) was defined as the lowest concentration of sample that caused complete inhibition of bacterial growth. It was determined based on a change in OD of $\leq 0.05$ at $600 \mathrm{~nm}$ during $24 / 48 \mathrm{~h}$ incubation; for the determination of minimum bactericidal concentration (MBC), $100 \mu \mathrm{L}$ sample was taken from wells where no growth was detected, and spread on agar plates and incubated at $37^{\circ} \mathrm{C}$ for $48 \mathrm{~h}$ for bacterial viable count. The MBC was defined as the lowest concentration found where there was $\geq 99.9 \%$ loss of viable cells [21].

A positive antibiotic control was prepared with bacteria in $100 \mu \mathrm{L}$ broth $+100 \mu \mathrm{L}$ penicillin $(10,000$ units $/ \mathrm{mL})$ and streptomycin $(10,000 \mu \mathrm{g} / \mathrm{mL})$ (GIBCO 15140, Invitrogen ${ }^{\mathrm{TM}}$, Waltham, MA, USA). A negative broth control was prepared with bacteria in $200 \mu \mathrm{L}$ broth. A further control was uninoculated broth $(200 \mu \mathrm{L})$ to test for sterility, all assays were performed in triplicate.

\subsection{Bacterial Cell Viability by LIVE/DEAD BacLight ${ }^{T M}$ Bacterial Viability Kit}

To distinguish between viable and non-viable bacterial cells following incubation with synthetic peptides, E. coli and L. acidophilus were stained using a LIVE/DEAD BacLight ${ }^{\mathrm{TM}}$ Bacterial viability kit, according to the supplier's instructions. Briefly, after 24 and $48 \mathrm{~h}$ incubation in an antibacterial activity assay, $200 \mu \mathrm{L}$ of solution containing bacterial cells from wells containing synthesized peptides at minimum inhibitory concentration (MIC) were separately transferred into a $1.5 \mathrm{~mL}$ microfuge tube, washed three times in sterile $0.85 \%(w / v) \mathrm{NaCl}$ and thoroughly mixed with Component $\mathrm{B}\left(\mathrm{SYTO}^{\circledR} 91.67 \mathrm{mM} /\right.$ propidium Iodide $18.3 \mathrm{mM}$ ), and incubated at room temperature in the dark for $15 \mathrm{~min}$. The viability of bacteria was then observed using a Nikon Epi 50i fluorescence microscope (FM), equipped with a UV lamp and a $100 \times$ magnification objective. The epifluorescence microscopy counts were performed directly on the film adhered to the slide. The results were expressed as the average number of cells per microscope field of view and calculated from counting 25 microscope fields of view. FM was set according to the manufacturer's description of excitation and emission profiles for the SYTO ${ }^{\circledR} 9$ and PI stains. The SYTO ${ }^{\circledR} 9$ greenfluorescent nucleic acid stain labels all bacteria, and the PI red-fluorescent nucleic acid stain only targets bacteria with damaged membrane. Using an appropriate mixture of these two dyes, bacteria with intact cytoplasm membrane stain fluorescent green, whereas bacteria with a damaged membrane stain fluorescent red. 


\subsection{Statistical Analysis}

Minitab version 17 statistical software (Minitab Inc., State College, PA, USA) was used for data analysis. For bacterial cell viability, the mean $\pm \mathrm{SD}$ were calculated from 25 fields from each slide. The data were subjected to one way analysis of variance (ANOVA), followed by the Sidak correction in General Linear Model to determine the significant differences between samples and broth control group, and intergroup comparisons, at $p<0.05$ level.

\section{Results}

\subsection{Chromatography Fractionation and Electrophoresis of Lf from Deer Milk}

The chromatogram obtained from the BioLogic DuoFlow cation exchange chromatography, which was used to isolate Lf from deer milk, is shown in Figure 1. Deer Lf was eluted with $20 \mathrm{mM}$ sodium dihydrogen phosphate buffer, $\mathrm{pH} 7.0$, containing $1.0 \mathrm{M} \mathrm{NaCl}$, corresponding to the third peak in Figure 1, and indicated that at $\mathrm{pH} 7$, deer Lf was substantially positively charged, in requiring elevated ionic strength to be eluted from the cation exchange resin. In Figure 2, the molecular weight of Lf from deer milk was found to be in the vicinity of 75-80 $\mathrm{kDa}$ by SDS-PAGE. With an overloaded loading of the LF protein on the SDS-PAGE, an additional protein band is evident between 20-25 kDa. Analysis of this lower band by in-gel digest mass spectrometry did not generate an identity.

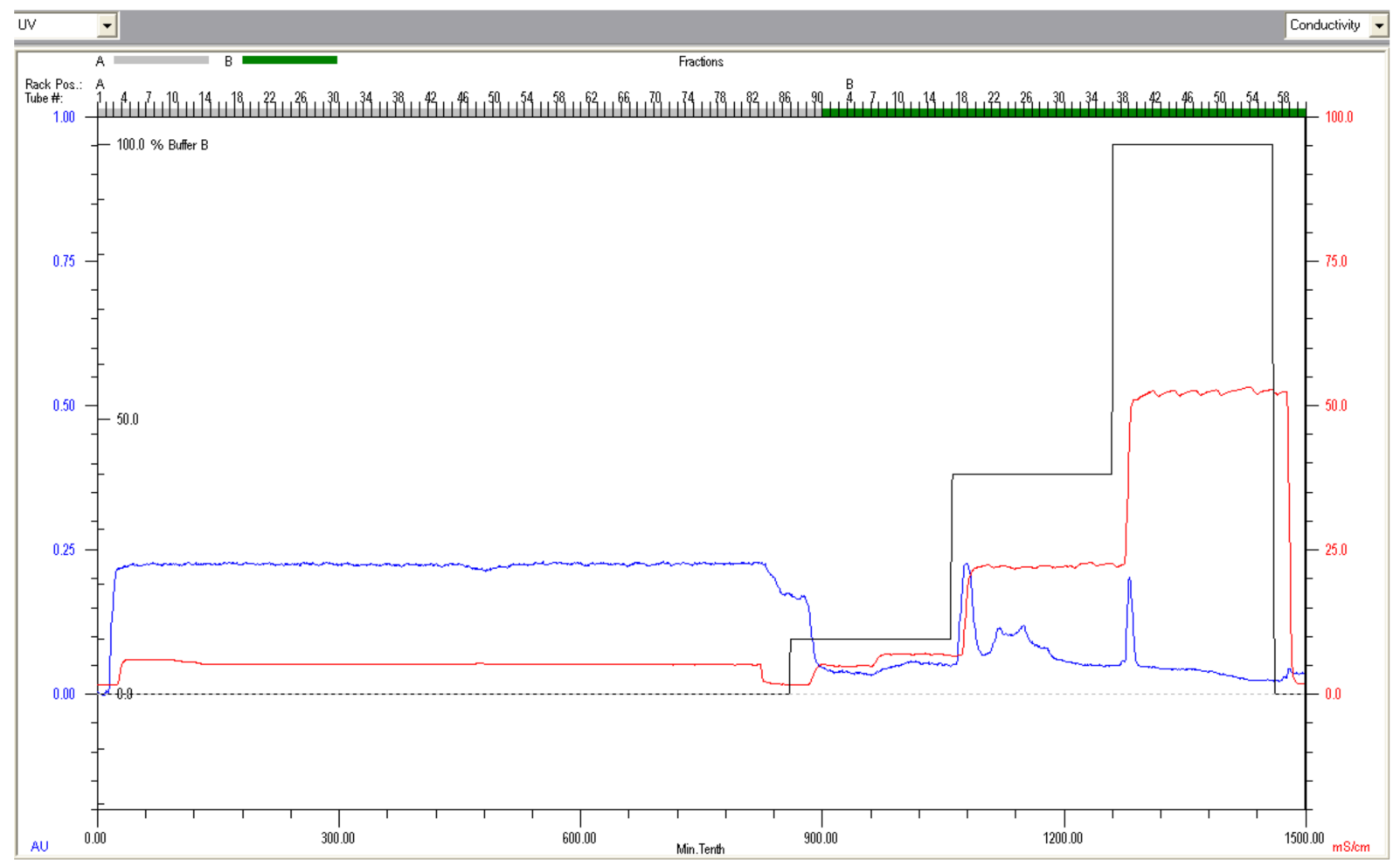

Figure 1. Fractionation of lactoferrin (Lf) from deer milk using cation exchange fast protein liquid chromatography (FPLC). 
Marker $\quad 1$

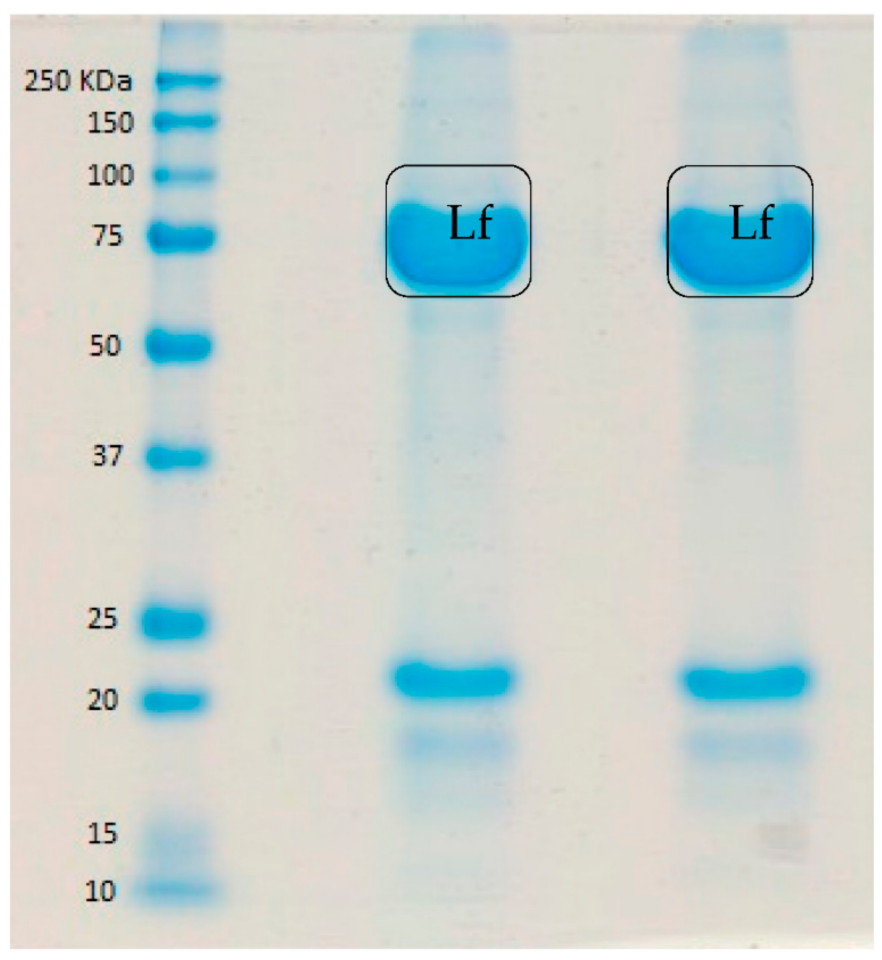

Figure 2. Sodium dodecyl sulfate-polyacrylamide acrylamide gel electrophoresis (SDS-PAGE) of lactoferrin (Lf) obtained by cation exchange chromatography from deer milk. Both lanes 1 and 2 are Lf isolated from deer milk.

The unbound deer whey protein fraction $(20 \mathrm{~mL})$ obtained from the first chromatography FPLC step was adjusted to $\mathrm{pH} 7.0$ and applied to a HiTrap SP-FF $5 \times 5 \mathrm{~mL}$ cartridge equilibrated in $20 \mathrm{mM}$ sodium dihydrogen phosphate at $\mathrm{pH} 7.0$, at a flow rate of $5 \mathrm{~mL} / \mathrm{min}$. The Lf protein was eluted with $20 \mathrm{mM}$ sodium dihydrogen phosphate, $\mathrm{pH} 7.0$, containing $1 \mathrm{M} \mathrm{NaCl}$.

\subsection{Amino Acid Sequence of Deer Lactoferrin}

The identification of the deer Lf obtained by chromatography was confirmed by in-gel digest mass spectrometry. The deer Lf amino acid sequence was obtained from a deer protein sequence database that was generated from a deer transcriptome analysis undertaken in-house in the Department of Biochemistry, University of Otago. The combined sequence coverage of tryptic, chymotryptic, and semi-chymotryptic peptides obtained was used to interrogate the in-house generated deer database and was found to achieve $65.21 \%$ coverage of the Lf amino acid sequence with matched peptides. The amino acid sequence of deer Lf which was generated from mRNA sequence is shown in Table 1, with comparison to the amino acid sequence of bovine Lf (PDB ID: 1BLF) [12]. Deer Lf was found to contain 707 amino acids, which is one amino acid less than the bovine Lf sequence. The primary structure of deer Lf was found to be $92 \%$ homologous with the bovine Lf sequence, with 55 differences in the amino acid sequence. The amino acid sequence of deer Lf reported in the present study, shows that it has a molecular weight of $77.1 \mathrm{kDa}$, that is lower than bovine Lf (78 kDa), and deer Lf has a slightly higher pI (7.99) than bovine Lf (7.9) [22]. 
Table 1. Comparison of the primary structures of deer lactoferrin (Lf) and bovine Lf.

\begin{tabular}{|c|c|}
\hline $\begin{array}{l}\text { Deer } \\
\text { Bovine }^{1} \\
1-60\end{array}$ & $\begin{array}{l}\text { MKLFV PALLA LGALG LCLAA PRKNV RWCAI SQPEW } \underline{\text { SKCYR WQWRM KKLGT PFVTC VRRTS }}{ }^{3} \\
\text { MKLFV PALLS LGALG LCLA }{ }^{2} \text { A PRKNV RWCTI SQPEW } \underline{\text { FKCRR WQWRM KKLGA PSITC VRRAF }}{ }^{4}\end{array}$ \\
\hline $\begin{array}{l}\text { Deer } \\
\text { Bovine } \\
61-120\end{array}$ & $\begin{array}{l}\text { ALECI RAIAA KKADA VTLDS GLVFE AGLDP YKLRP VAAEI YGTEK SPQTH YYAVA VVKKG } \\
\text { ALECI RAIAE KKADA VTLDG GMVFE AGRDP YKLRP VAAEI YGTKE SPQTH YYAVA VVKKG }\end{array}$ \\
\hline
\end{tabular}

\begin{tabular}{ll}
\hline Deer & SNFQL DQLQG RKSCH TGLGR SAGWN IPIGI LRPSL GWTES LEPLQ GAVAK FFSAS CVPCV \\
Bovine & SNFQL DQLQG RKSCH TGLGR SAGWI IPMGI LRPYL SWTES LEPLQ GAVAK FFSAS CVPCI \\
$121-180$ &
\end{tabular}

\begin{tabular}{ll}
\hline Deer & DGKAY PNLCQ LCKGT GENQC ACSPR EPY_G YSGAF RCLQE GAGDV AFVKE TTVFE NLPEK \\
Bovine & DRQAY PNLCQ LCKGE GENQC ACSSR EPYFG YSGAF KCLQD GAGDV AFVKE TTVFE NLPEK \\
$181-240$ &
\end{tabular}

\begin{tabular}{ll}
\hline Deer & ADRDQ YELLC LNNSR APVDA FKECH LAQVP SHAVV ARSVD GKEDL IWQLL SKAQE KFGKN \\
Bovine & ADRDQ YELLC LNNSR APVDA FKECH LAQVP SHAVV ARSVD GKEDL IWKLL SKAQE KFGKN \\
$241-300$ &
\end{tabular}

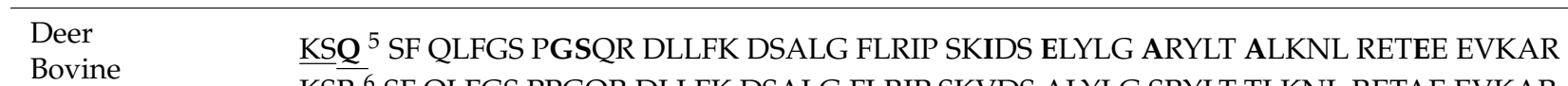

Bovine $\quad \underline{\mathrm{KSR}}^{6}$ SF QLFGS PPGQR DLLFK DSALG FLRIP SKVDS ALYLG SRYLT TLKNL RETAE EVKAR

\begin{tabular}{ll}
\hline Deer & STRVV WCAVG PEEQK KCQQW SQQSD QSVTC ATAST TDDCI ALVLK GEADA LSLDG GYIYT \\
Bovine & YTRVV WCAVG PEEQK KCQQW SQQSG QNVTC ATAST TDDCI VLVLK GEADA LNLDG GYIYT \\
$361-420$ & \\
\hline
\end{tabular}

\begin{tabular}{ll}
\hline Deer & AGKCG LVPVM AENRK SSKDS SLDCV LRPTE GYLAV AVVKK ANEGL TWNSL KGKKS CHTAV \\
Bovine & AGKCG LVPVL AENRK SSKHS SLDCV LRPTE GYLAV AVVKK ANEGL TWNSL KDKKS CHTAV \\
$421-480$ & \\
\hline
\end{tabular}

\begin{tabular}{ll}
\hline Deer & DRTAG WNIPM GLIAN QTGSC KFDEF FSQSC APGAD PKSSL CALCA GDDQG LDKCV PNTKE \\
Bovine & DRTAG WNIPM GLIVN QTGSC AFDEF FSQSC APGAD PKSRL CALCA GDDQG LDKCV PNSKE \\
$481-540$ &
\end{tabular}

\begin{tabular}{ll}
\hline Deer & KYYGY TGAFR CLAED VGDVA FVKND TVWEN TNGES SADWA KNLNR EDFRL LCLDG TRKPV \\
Bovine & KYYGY TGAFR CLAED VGDVA FVKND TVWEN TNGES TADWA KNLNR EDFRL LCLDG TRKPV \\
$541-600$ &
\end{tabular}

\begin{tabular}{|c|c|}
\hline Deer & TEAQS CHLAA APSHA VVSRS DRAAH VEQVL LHQQA LFGRN GKDCP DKFCL FKSET KNLLF \\
\hline $\begin{array}{l}\text { Bovine } \\
601-660\end{array}$ & TEAQS CHLAV APNHA VVSRS DRAAH VKQVL LHQQA LFGKN GKNCP DKFCL FKSET KNLLF \\
\hline
\end{tabular}

$\begin{array}{ll}\text { Deer } & \text { NDNTR CLAKL GGRPT YEKYL GTEYV TAIAN LKKCS TSPLL EACAF LTR } \\ \text { Bovine } & \text { NDNTE CLAKL GGRPT YEEYL GTEYV TAIAN LKKCS TSPLL EACAF LTR }\end{array}$

$661-708$

Letters in bold indicate differences in the amino acid sequence in deer lactoferrin (Lf) compared to bovine Lf. ${ }^{1}$ The amino acid sequence of bovine Lf was obtained from UniProtKB-P24627. ${ }^{2}$ The first 19 amino acids of bovine Lf is signal peptide sequence that is cleaved at Ala19-Ala20 to yield the mature bovine Lf [7]. The numbering of the peptides below is with respect to the mature Lf sequence. ${ }^{3}$ Underlined deer Lfcin $\mathrm{f}(17-41) .{ }^{4}$ Underlined bovine Lfcin $\mathrm{f}(17-41) .{ }^{5}$ Underlined deer Lfampin $\mathrm{f}(265-284) .{ }^{6}$ Underlined bovine Lfampin $\mathrm{f}(265-284)$.

Characteristics of Deer Lactoferricin and Lactoferrampin

Modelled 3-D structures of deer Lfcin and Lfampin were found to be similar to that of the bovine Lfcin and Lfampin structures (Figure 3). The amino acid sequences of Lfcin (17-41) from deer and bovine Lf share $72 \%$ homology. Deer Lfcin has seven positively charged amino acids and bovine Lfcin has eight positively charged amino acids. There are nine hydrophobic residues and nine hydrophilic residues in deer Lfcin. However, bovine Lfcin has two more hydrophobic residues than deer Lfcin. The high overall positive charge of peptides with a net charge of at least +4 and hydrophobic residues are reported to be important for antibacterial activity of bovine Lfcin [23,24]. Deer Lfcin possesses similar characteristics of positive charge and hydrophobic residues which indicate deer Lfcin should exhibit antibacterial activity like bovine Lfcin. But due to different numbers of 
positively charged amino acids and hydrophobic residues in deer Lfcin, it might have differences in binding to the bacterial cell wall, resulting in a difference in activity.
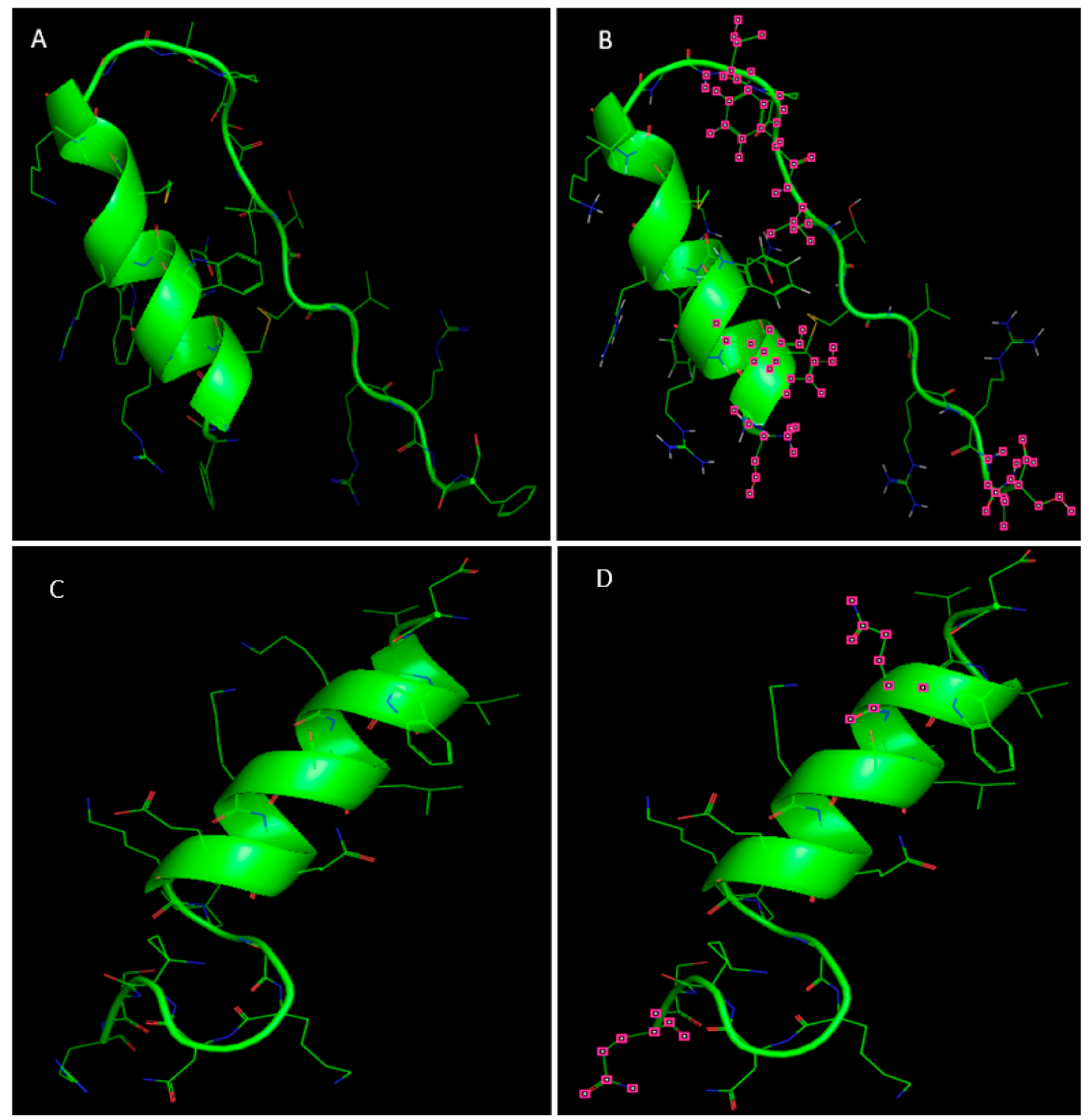

Figure 3. In silico structures of deer and bovine lactoferricin (Lfcin) and lactoferrampin (Lfampin). (A) Structure of bovine Lfcin (FKCRRWQWRMKKLGAPSITCVRRAF) (PDB ID: 1BLF); (B) Structure of deer Lfcin (SKCYRWQWRMKKLGTPFVTCVRRTS) displayed using PyMOL; (C) Structure of bovine Lfampin (265-284) (DLIWKLLSKAQEKFGKNKSR) (PDB ID: 1BLF); (D) Structure of deer Lfampin (265-284) (DLIWQLLSKAQEKFGKNKSQ) displayed using PyMOL. Pink squares indicate differences between deer and bovine Lfcin and Lfampin.

Deer and bovine Lfampin are homologous, apart from difference in two different amino acids, resulting in 90\% similarity. Basic amino acids, Lys and Arg, in bovine Lfampin are replaced with amide amino acids in deer Lfampin. There are four positively charged amino acids in deer Lfampin and six in bovine Lfampin. Both peptides have seven hydrophobic residues. 


\subsection{Antibacterial Activities of Synthesized Peptides Lactoferricin and Lactoferrampin on Bacterial Growth}

Deer and bovine Lfcin and Lfampin at different concentrations were tested against $E$. coli ATCC 25922, S. aureus ATCC 23923, and L. acidophilus ATCC 4356. The MIC of deer Lfcin against E. coli ATCC 25922 was found to be $240 \mu \mathrm{g} / \mathrm{mL}$ and the MBC was found to be the same (Table 2). Bovine Lfcin was found to be $120 \mu \mathrm{g} / \mathrm{mL}$ for both the MIC and the MBC for E. coli ATCC 25922 (Table 2). Deer Lfampin, within the concentration range from 15 to $480 \mu \mathrm{g} / \mathrm{mL}$, promoted E. coli ATCC 25922 growth. The MIC, as well as MBC of bovine Lfampin against E. coli ATCC 25922 was found to be $480 \mu \mathrm{g} / \mathrm{mL}$. These results indicate that at an equivalent concentration, bovine Lfcin and Lfampin were more active as antimicrobial inhibitors of E. coli ATCC 25922 growth than deer Lfcin and Lfampin.

Table 2. Minimum Inhibitory Concentrations (MIC) $(\mu \mathrm{g} / \mathrm{mL})$ of deer and bovine lactoferricin (Lfcin) and lactoferrampin (Lfampin) against E. coli ATCC 25922, S. aureus ATCC 25923, and L. acidophilus ATCC 4356. The Minimum Bactericidal Concentrations (MBC) values were found to be the same as that of the MIC values.

\begin{tabular}{ccccc}
\hline & \multicolumn{2}{c}{ Lfcin } & \multicolumn{2}{c}{ Lfampin } \\
\cline { 2 - 5 } & Deer & Bovine & Deer & Bovine \\
\hline E. coli ATCC 25922 & $240^{\mathrm{b}}$ & $120^{\mathrm{a}}$ & $>960^{\mathrm{d}}$ & $480^{\mathrm{c}}$ \\
S. aureus ATCC 25923 & $>960$ & $>960^{\mathrm{b}}$ & $>960$ & $>960^{\mathrm{b}}$ \\
L. acidophilus ATCC 4356 & $480^{\mathrm{a}}$ & $>960^{\mathrm{b}}$ & $>960^{\mathrm{b}}$ & $>960^{\mathrm{b}}$ \\
\hline
\end{tabular}

$\overline{\mathrm{a}-\mathrm{d}}$ means with different superscripts are significantly different at $p<0.05$.

Although no MICs were achieved within the tested concentrations $(30-480 \mu \mathrm{g} / \mathrm{mL})$ for deer or bovine Lfcin and Lfampin against S. aureus ATCC 25923, the lag time and generation time of $S$. aureus was found to increase in the presence of deer and bovine Lfcin at 240 and $480 \mu \mathrm{g} / \mathrm{mL}$ respectively. This indicates that both deer and bovine Lfcin slowed the growth of S. aureus. The MIC of deer Lfcin against L. acidophilus ATCC 4356 was found to be $480 \mu \mathrm{g} / \mathrm{mL}$. At the same concentration, deer Lfcin showed more active antimicrobial inhibitory ability against $L$. acidophilus ATCC 4356 than did bovine Lfcin. Deer Lfampin was also more active against L. acidophilus ATCC 4356 than was bovine Lfampin at the same concentration, but no MICs were achieved.

The effects of deer Lfcin at $240 \mu \mathrm{g} / \mathrm{mL}$, bovine Lfcin at $120 \mu \mathrm{g} / \mathrm{mL}$, and bovine Lfampin at $480 \mu \mathrm{g} / \mathrm{mL}$ on E. coli ATCC 25922 viability at 0 and $24 \mathrm{~h}$ in the antimicrobial activity tests are shown in Figure 4. Green colored bacterial cells indicate an intact bacterial membrane, which at $0 \mathrm{~h}$ indicate that the bacteria were viable. After $24 \mathrm{~h}$ of exposure to antimicrobial peptide, the E. coli cells exhibited a red color. This indicated that E. coli ATCC 25922 bacteria were non-viable following exposure to the antimicrobial peptides. The antibiotics penicillin $(10,000$ units $/ \mathrm{mL})$ and streptomycin $(10,000 \mu \mathrm{g} / \mathrm{mL})$ were used as controls. Figure $4 \mathrm{D}$ shows the $E$. coli cell viability at 0 and $24 \mathrm{~h}$ in the presence of antibiotics. It can be concluded that these three peptides at their MICs had an equivalent inhibitory effect on E. coli ATCC 25922 as did the antibiotics.

L. acidophilus ATCC 4356 cell viability in the presence of deer Lfcin at $480 \mu \mathrm{g} / \mathrm{mL}$ at 0 and $24 \mathrm{~h}$ was compared with treatment with the antibiotics penicillin $(10,000$ units $/ \mathrm{mL})$ and streptomycin $(10,000 \mu \mathrm{g} / \mathrm{mL})$, along with an MRS broth control group. Figure $4 \mathrm{~F}$ shows most of the L. acidophilus cells were viable (green) with only a few non-viable (red) at $0 \mathrm{~h}$. After $24 \mathrm{~h}$, although the number of bacterial cells increased, most of the bacteria were found to be non-viable following exposure to deer Lfcin at $480 \mu \mathrm{g} / \mathrm{mL}$. With the antibiotic treatment, the bacterial viability at $0 \mathrm{~h}$ was the same as that of deer Lfcin in which most of the bacteria were viable, but at $24 \mathrm{~h}$ were non-viable, indicating that the antibiotics were more effective at inhibiting L. acidophilus growth than was deer Lfcin at $480 \mu \mathrm{g} / \mathrm{mL}$. In Figure $4 \mathrm{H}$ for the MRSc broth control group, the majority of bacterial cells were viable at $0 \mathrm{~h}$. After $24 \mathrm{~h}$, there were more bacteria in the field and viable bacterial cells still outnumbered 
non-viable cells. Due to the variable dimensions of L. acidophilus that were observed in the microscope field, bacterial cell numbers could not be accurately determined.

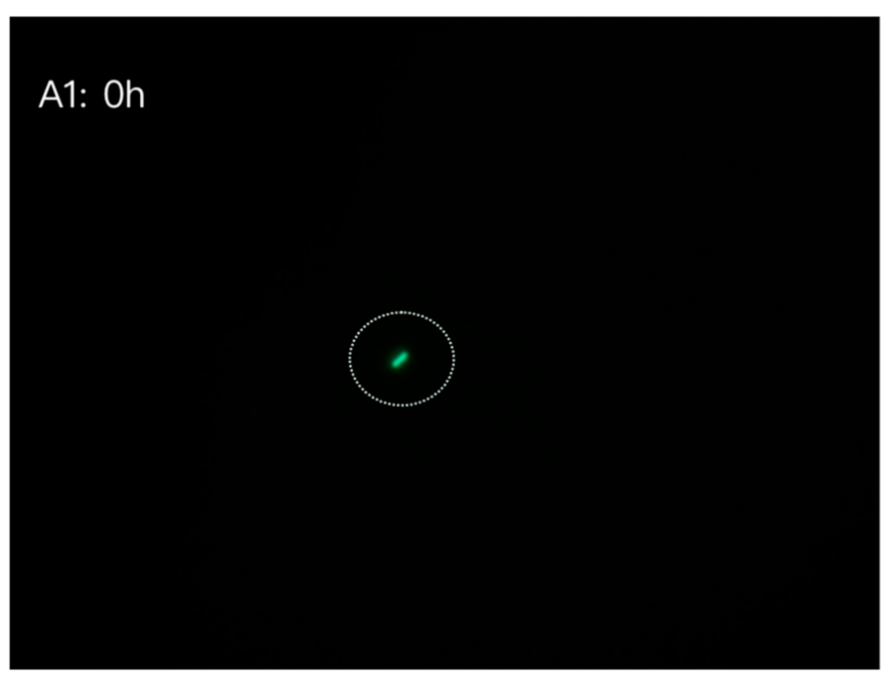

A2: $24 h$

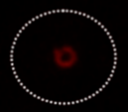

B1: Oh

B2: $24 \mathrm{~h}$
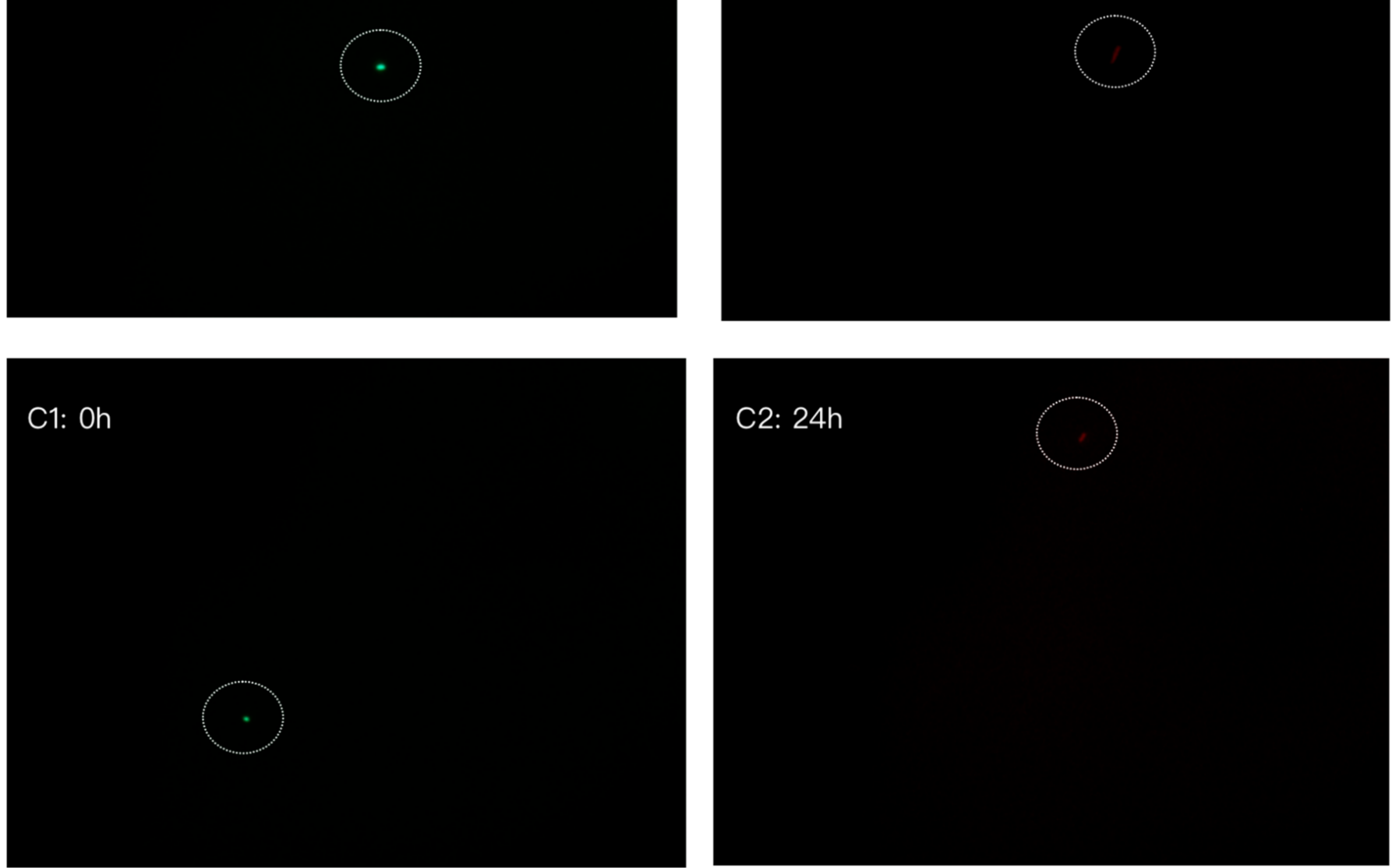

Figure 4. Cont. 
D1: Oh

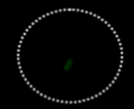

D2: $24 \mathrm{~h}$

E1: Oh

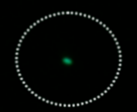

E2: $24 \mathrm{~h}$, diluted 100 times

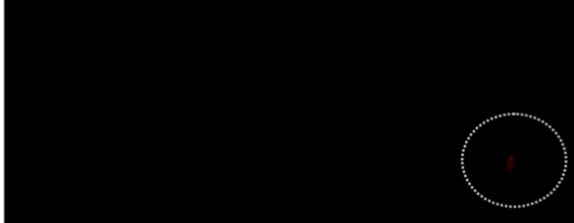

F1: Oh

F2: $24 h$

Figure 4. Cont. 

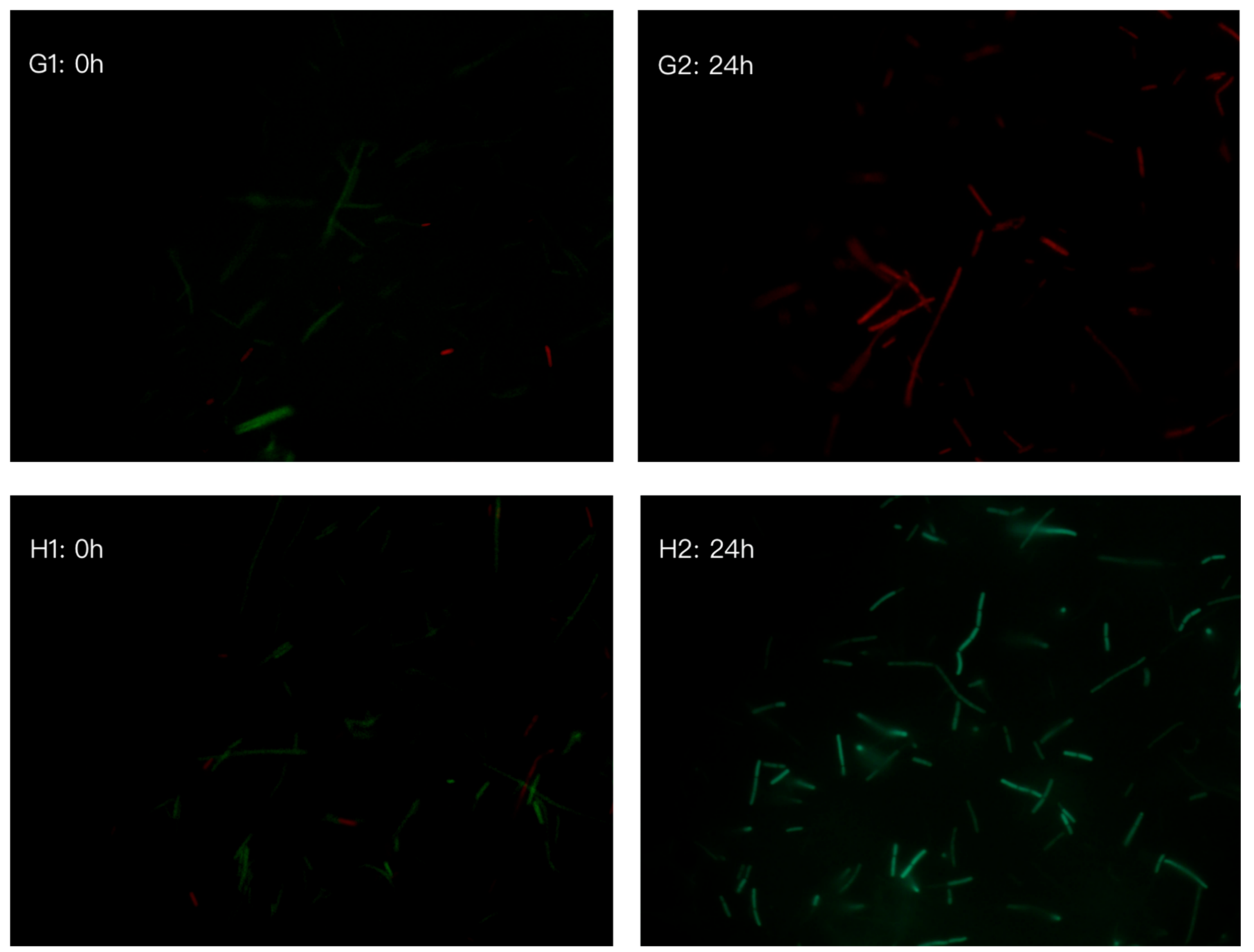

Figure 4. Bacterial viability determined using the LIVE/DEAD BacLight ${ }^{\mathrm{TM}}$ Bacterial viability kit. Incubation with lactoferricin (Lfcin) and lactoferrampin (Lfampin) at 0 and $24 \mathrm{~h}$. (A) E. coli ATCC 25922 incubated with deer Lfcin $240 \mu \mathrm{g} / \mathrm{mL}$. (B) E. coli ATCC 25922 incubated with bovine Lfcin $120 \mu \mathrm{g} / \mathrm{mL}$. (C) E. coli ATCC 25922 incubated with bovine Lfampin $480 \mu \mathrm{g} / \mathrm{mL}$. (D) E. coli ATCC 25922 incubated with penicillin (10,000 units $/ \mathrm{mL})$ and streptomycin $(10,000 \mu \mathrm{g} / \mathrm{mL})$. (E) E. coli ATCC 25922 incubated with nutrient broth. (F) L. acidophilus ATCC4356 incubated with deer Lfcin $480 \mu \mathrm{g} / \mathrm{mL}$. (G) L. acidophilus ATCC4356 incubated with penicillin $(10,000$ units $/ \mathrm{mL})$ and streptomycin $(10,000 \mu \mathrm{g} / \mathrm{mL})$. (H) L. acidophilus ATCC4356 incubated with MRSc broth. Green fluorescence indicates viable bacteria, red fluorescence indicates non-viable bacteria. Microscope magnification $\times 1000$.

\section{Discussion}

Lfcin, which is located in the N-domain of bovine Lf, can be produced by gastric pepsin cleavage of Lf [25]. It is a 25-amino-acid peptide that has a high proportion of basic residues, with a net charge of +8 , and amphipathic properties [26]. The ability of Lfcin to form amphipathic structures with net hydrophobic and positively charged surfaces is a trait that is shared with other peptides having antimicrobial activity [27]. As Arg can interact both electrostatically and through multiple hydrogen bonds with the negatively charged surface of bacteria, it is thought that this amino acid is the most effective target in antimicrobial peptides to interact with the bacterial membrane [28]. Once this interaction occurs, the hydrophobic residues interact with the lipophilic portion of the membrane, becoming embedded into its surface and destabilizing the packing of the membrane phospholipids. Of the hydrophobic residues present in Lfcin, Trp is clearly important. The bactericidal activity of bovine Lfcin appears to be dependent on not just one Trp but on 
at least two [23]. Trp acts as an anchor with the bulk of Lfcin residues helping to bind the peptide to the membrane. The importance of Arg and Trp for the antibacterial activity of Lfcin highlights the importance of both electrostatic and hydrophobic interactions for the activity of Lfcin. The in silico modelling of deer Lfcin indicated a very similar $\alpha$-helical structure compared to bovine Lfcin. Deer Lfcin has four Arg, one less than bovine Lfcin, that could interact with the bacterial membrane. One Arg in bovine Lfcin is replaced by Tyr in deer Lfcin. Both deer and bovine Lfcin have two Trp residues facilitating hydrophobic interaction with the bacterial membrane. The amino acid sequences predict that deer Lfcin could have similar antibacterial activity as bovine Lfcin.

Deer Lfampin has the common features of antimicrobial peptides with a high net positive charge, a hydrophobic domain and hence an amphipathic character. Although both Lfampin and Lfcin share amphipathic and cationic features, the bactericidal activity of Lfampin differs from that of Lfcin. Deer Lfampin has a different amino acid composition and chain length, hence its modelled structure differs somewhat from Lfcin. Bovine Lfampin is a more recently identified antimicrobial peptide compared to Lfcin and has been less studied in relation to its mechanism of antimicrobial activity. It has cationic amino acid residues with the hydrophobic domain containing Trp that is involved in membrane insertion [14]. The predicted amphipathic helical conformation of this peptide is a common motif for bioactivity against Gram-positive bacteria [29]. Trp 268 is reported to insert into the membrane at the lipid/water interface and the phenyl side chain of Phe 278 is oriented in the same direction as the indole ring of Trp 268, allowing these two residues to anchor the peptide into the lipid bilayer [29]. The amphipathic N-terminal helix is reported to anchor bovine Lfampin to the surface of the bacterial membrane with the hydrophobic side chains of Trp 268 and Phe 278 playing important roles in stabilizing the interaction and for inducing peptide folding [30]. Deer Lfampin 265-284 has both Trp 268 and Phe 278 , which may be involved in membrane insertion during antimicrobial activity. Deer Lfampin Phe 278 could play an important role of interaction between the peptide and a negatively charged microbial cell membrane, while the helix capping residues, including Trp 268, could penetrate into the hydrophobic core of a membrane lipid bilayer.

Bovine Lfcin antimicrobial activity has been reported against $E$. coli ATCC 25922 within the range of MIC 3.3 to $30 \mu \mathrm{g} / \mathrm{mL}$ [11]. The variation of MIC of bovine Lfcin against E. coli could be related to the method used for determining the MIC, different broth, different strains, and source of Lfcin (pepsin hydrolyzed or chemically synthesized). Previously, simulated gastrointestinal hydrolysis of un-fractionated hydrolysates conducted in our laboratory, of deer Lf were found to exhibit differences in antibacterial activity compared to unfractionated hydrolysates of bovine Lf. In the present study, for synthetic deer Lfcin, the MIC against $E$. coli ATCC 25922 was found to be $240 \mu \mathrm{g} / \mathrm{mL}$ which was twice that of bovine Lfcin MIC in this study. Bovine Lfcin has more positive charged and hydrophobic residues than deer Lfcin. The difference in amino acid sequences of peptides suggests bovine Lfcin might have stronger antibacterial activity than deer Lfcin. This assumption was confirmed by the antimicrobial activity results, that indicated bovine Lfcin was more effective than deer Lfcin, at the same concentration, against E. coli ATCC 25922. Vorland et al. (1998) found the antimicrobial activity of bovine Lfcin (MIC $90 \mu \mathrm{g} / \mathrm{mL}$ ) was more effective against $E$. coli ATCC 25922 than human (MIC $>200 \mu \mathrm{g} / \mathrm{mL}$ ), murine (MIC $>200 \mu \mathrm{g} / \mathrm{mL}$ ), and caprine (MIC $>200 \mu \mathrm{g} / \mathrm{mL}$ ) Lfcins [31]. These Lfcins were in linear form. Cyclic bovine Lfcin was found to be more active than linear bovine Lfcin against E. coli ATCC 25922 and S. aureus ATCC 25923. The effect of bovine Lfcin was decreased by reducing the cysteine disulfides. However, another report studying a fragment of bovine Lfcin consisting of 11 amino acids showed that the disulfide bridge is not essential for activity [32]. The motif RRWQWR is the minimum described sequence that exhibits antibacterial activity in bovine Lfcin. This motif is amphipathic, with the hydrophilic face being positive charged due to the presence of Arg side chains, while the hydrophobic face has Trp side chains [33]. Also, an even shorter motif RWQWR from bovine Lfcin was reported to exhibit a high and specific activity against E. coli ATCC 11775 [34]. The (R)RWQWR motif is 
encrypted in both deer Lfcin (SKCYRWQWRMKKLGTPFVTCVRRTS) and bovine Lfcin (FKCRRWQWRMKKLGAPSITCVRRAF), which could explain the antimicrobial activity exhibited by deer Lfcin found in the present study. Deer Lfcin contains positive charged and hydrophobic amino acid residues which are reported to be important for association and penetration of the bacterial membrane. More specifically, deer Lfcin contains the basic amino acid Arg which has the ability to interact with a negatively charged bacterial membrane, and two Trp that can enhance hydrophobic interaction of the peptide with a bacterial membrane.

The four peptides, Lfcin and Lfampin from deer and bovine, were not effective against S. aureus ATCC 25923 within the concentration range from 30 to $480 \mu \mathrm{g} / \mathrm{mL}$ in this study. It has been reported that the MIC of cyclic and linear bovine Lfcin against S. aureus ATCC 25923 was 30 and $90 \mu \mathrm{g} / \mathrm{mL}$, respectively [31]. Different bacterial cell density, culture broth, and peptide structures may explain the different results obtained in the present study.

L. acidophilus ATCC 4356 was chosen as a representative of probiotic bacteria from human gut microbiota. Deer and bovine Lfcin and Lfampin were tested on L. acidophilus in order to investigate the effect of these antimicrobial peptides on bacteria which colonize the human gut. Deer Lfcin at $480 \mu \mathrm{g} / \mathrm{mL}$ reached the MIC against L. acidophilus. The present study showed the inhibitory activity of deer and bovine Lfcin and Lfampin on L. acidophilus growth. Chen et al. (2013) found L. acidophilus ATCC 4356 was inhibited by both bovine Lf and its hydrolysate with MIC $16 \mathrm{mg} / \mathrm{mL}$ for $24 \mathrm{~h} \mathrm{[35].} \mathrm{In} \mathrm{the} \mathrm{present} \mathrm{study,} \mathrm{deer} \mathrm{and}$ bovine Lfcin and Lfampin not only inhibited food-pathogenic bacteria (e.g., E. coli and S. aureus), but also probiotic bacteria.

The plate count method is routinely used in the determination of microbial viability. It is based upon the premise that a single bacterium can grow and divide to produce an entire colony. Microbial cells may exist in cryptobiotic, dormant, moribund, or latent states, in which they will not form colonies on nutrient media but may have other measurable activity [36]. No method exists that demonstrates with absolute certainty whether an organism is alive or dead. It is argued that the presence of intact and functional nucleic acids, as well as an intact and polarized cytoplasmic membrane are essential components of cellular viability. The membrane integrity stain LIVE/DEAD Baclight ${ }^{\mathrm{TM}}$ is not a measure of life or death but assesses particular location-specific damage to cells. Both SYTO9 and PI stain nucleic acids. Green fluorescent SYTO9 generally labels all bacteria in a population, both those with intact membranes and those with damaged membranes. In contrast, red fluorescent PI which is a relatively large (668 Da) and double-charged dye, penetrates only bacteria with damaged cytoplasmic membranes, causing a reduction in the SYTO9 stain fluorescence when both dyes are present [37]. Thus, with an appropriate mixture of the SYTO9 and PI stains, bacteria with intact cell membranes stain fluorescent green, whereas bacteria with damaged membranes stain fluorescent red. The emission properties of the stain mixture bound to DNA change due to the displacement of SYTO9 by PI and quenching of SYTO9 emissions by fluorescence resonance energy transfer [38].

In addition to penetrating the cell wall and cell membrane of bacteria, bovine Lfcin can inhibit bacteria by affecting intracellular activity, by attacking the transcription-related activities and several cellular carbohydrate biosynthetic processes (DNA, RNA and protein synthesis), and can ultimately result in cell death in both Gram-negative and Gram-positive bacteria [39]. The present results of red fluorescence exhibited by E. coli ATCC 25922 and L. acidophilus ATCC 4356 after exposure to antimicrobial peptides for $24 \mathrm{~h}$ in the assays, showed that the bacterial cell membrane was damaged by deer Lfcin at $240 \mu \mathrm{g} / \mathrm{mL}$, bovine Lfcin at $120 \mu \mathrm{g} / \mathrm{mL}$, and bovine Lfampin and deer Lfcin at $480 \mu \mathrm{g} / \mathrm{mL}$. Trp and Phe in bovine Lfampin have been reported to damage the integrity of the bacterial cell membrane [30], which was observed in the present study by the red fluorescence of $E$. coli ATCC 25922 treated with bovine Lfampin at $480 \mu \mathrm{g} / \mathrm{mL}$. 


\section{Conclusions}

Deer Lf was successfully fractionated from deer milk using cation exchange chromatography. Deer Lf was found to have a slightly higher isoelectric point (pI) of 7.99 compared to bovine Lf (pI 7.9). Deer Lf was found to contain 707 amino acids with a MW $77.1 \mathrm{kDa}$, with one less amino acid than bovine Lf (78 kDa). The deer Lf sequence was found to be $92 \%$ homologous to that of bovine Lf. Deer Lfcin and Lfampin share $72 \%$ and $90 \%$ similarities with bovine Lfcin and Lfampin, respectively. Deer Lfcin, bovine Lfcin and Lfampin exhibited strong inhibitory activity against E. coli ATCC 25922 with MICs of 240,120, and $480 \mu \mathrm{g} / \mathrm{mL}$ respectively. Bovine Lfcin and Lfampin exhibited stronger antimicrobial activity than deer Lfcin and Lfampin against E. coli ATCC 25922 at the same concentrations. The MIC of deer Lfcin against L. acidophilus ATCC 4356 was $480 \mu \mathrm{g} / \mathrm{mL}$ in the present study. L. acidophilus ATCC 4356 was more susceptible to inhibition by deer Lfcin than bovine Lfcin. Although both deer Lfcin and Lfampin have amphipathic and cationic features, the antibacterial activities differ from that of bovine Lfcin and Lfampin, respectively, likely because they have different numbers of positive charged and hydrophobic residues which play important roles in the binding and penetration of the bacterial membrane in eliciting the antimicrobial activity.

Author Contributions: Y.W., A.E.-D.A.B., J.D.M., A.C., and S.L.M. conceived and designed the experiments; Y.W. and A.C. performed the experiments; Y.W. analyzed the data; Y.W., A.E.-D.A.B., J.D.M., A.C., and S.L.M. contributed reagents/materials/analysis tools; Y.W. wrote the paper. All authors have read and agreed to the published version of the manuscript.

Funding: This research received no external funding.

Institutional Review Board Statement: Not applicable.

Informed Consent Statement: Not applicable.

Data Availability Statement: The datasets generated for this study are available on request to the corresponding author.

Conflicts of Interest: The authors declare that they have no competing conflicts of interest.

\section{References}

1. Giacometti, A.; Cirioni, O.; Barchiesi, F.; Del Prete, M.S.; Scalise, G. Antimicrobial activity of polycationic peptides. Peptides 1999, 20, 1265-1273. [CrossRef]

2. Bechinger, B.; Gorr, S.U. Antimicrobial Peptides: Mechanisms of Action and Resistance. J. Dent. Res. 2017, 96, 254-260. [CrossRef] [PubMed]

3. Nielsen, S.D.; Beverly, R.L.; Qu, Y.; Dallas, D.C. Milk bioactive peptide database: A comprehensive database of milk proteinderived bioactive peptides and novel visualization. Food Chem. 2017, 232, 673-682. [CrossRef] [PubMed]

4. Wang, Y.; Bekhit, A.E.-D.A.; Mason, S.L.; Morton, J.D. Nutritional value of deer milk. In Nutrients in Dairy and Their Implications on Health and Disease; Watson, R.R., Collier, R.J., Preedy, V.R., Eds.; Elsevier BV: Amsterdam, The Netherlands, 2017 ; pp. 363-375.

5. Wang, Y.; Bekhit, A.E.-D.A.; Mason, S.L.; Morton, J.D. Lactoferrin isolation and hydrolysis from red deer (Cervus elaphus) milk and the antibacterial activity of deer lactoferrin and it hydrolysates. Foods 2020, 9, 1711. [CrossRef] [PubMed]

6. Franco, I.; Perez, M.D.; Conesa, C.; Calvo, M.; Sanchez, L. Effect of technological treatments on bovine lactoferrin: An overview. Food Res. Intern. 2018, 106, 173-182. [CrossRef]

7. Goodman, R.E.; Schanbacher, F.L. Bovine lactoferrin mRNA: Sequence, analysis, and expression in the mammary gland. Biochem. Biophys. Res. Commun. 1991, 180, 75-84. [CrossRef]

8. Masson, P.L.; Heremans, J.F.; Prignot, J.J.; Wauters, G. Immunohistochemical localization and bacteriostatic properties of an iron-binding protein from bronchial mucus. Thorax 1966, 21, 538-544. [CrossRef]

9. Barbiroli, A.; Bonomi, F.; Capretti, G.; Iametti, S.; Manzoni, M.; Piergiovanni, L.; Rollini, M. Antimicrobial activity of lysozyme and lactoferrin incorporated in cellulose-based food packaging. Food Control 2012, 26, 387-392. [CrossRef]

10. Valenti, P.; Antonini, G. Lactoferrin: An important host defence against microbial and viral attack. Cell. Mol. Life Sci. 2005, 62, 2576-2587. [CrossRef] [PubMed]

11. Bruni, N.; Capucchio, M.T.; Biasibetti, E.; Pessione, E.; Cirrincione, S.; Giraudo, L.; Corona, A.; Dosio, F. Antimicrobial activity of lactoferrin-related peptides and applications in human and veterinary medicine. Molecules 2016, 21, 752. [CrossRef]

12. Protein Data Bank. Available online: https:/ / www.rcsb.org (accessed on 26 April 2021).

13. Bellamy, W.; Takase, M.; Yamauchi, K.; Wakabayashi, H.; Kawase, K.; Tomita, M. Identifification of the bactericidal domain of lactoferrin. Biochim. Biophys. Acta (BBA) Protein Struct. Mol. Enzymol. 1992, 1121, 130-136. [CrossRef] 
14. van der Kraan, M.I.A.; Groenink, J.; Nazmi, K.; Veerman, E.C.I.; Bolscher, J.G.M.; Amerongen, A.V.N. Lactoferrampin: A novel antimicrobial peptide in the N1-domain of bovine lactoferrin. Peptides 2004, 25, 177-183. [CrossRef]

15. Pilbrow, J.; Bekhit, A.E.-D.A.; Carne, A. Fractionation of sheep cheese whey by a scalable method to sequentially isolate bioactive proteins. Food Chem. 2016, 203, 165-174. [CrossRef] [PubMed]

16. Laemmli, U.K. Cleavage of structural proteins during the assembly of the head of bacteriophage T4. Nature 1970, 227, 680-685. [CrossRef] [PubMed]

17. Shevchenko, A.; Jensen, O.N.; Podtelejnikov, A.V.; Sagliocco, F.; Wilm, M.; Vorm, O.; Mortensen, P.; Shevchenko, A.; Boucherie, H.; Mann, M. Linking genome and proteome by mass spectrometry: Large-scale identification of yeast proteins from two dimensional gels. Proc. Natl. Acad. Sci. USA 1996, 93, 14440-14445. [CrossRef] [PubMed]

18. Ha, M.; Sabherwal, M.; Duncan, E.; Stevens, S.; Stockwell, P.; McConnell, M.; Bekhit, A.E.D.; Carne, A. In-depth characterization of sheep (Ovis aries) milk whey proteome and comparison with cow (Bos taurus). PLoS ONE 2015, 10, e0139774. [CrossRef]

19. Mascot Search Engine. Available online: https://www.matrixscience.com (accessed on 26 April 2021).

20. Hasselmann, C.; European Soc Clinical, M. Determination of minimum inhibitory concentrations (MICs) of antibacterial agents by broth dilution. Clin. Microbiol. Infect. 2003, 9, ix-xv.

21. Conesa, C.; Sanchez, L.; Rota, C.; Perez, M.D.; Calvo, M.; Farnaud, S.; Evans, R.W. Isolation of lactoferrin from milk of different species: Calorimetric and antimicrobial studies. Comp. Biochem. Physiol. Part B Biochem. Mol. Biol. 2008, 150, 131-139. [CrossRef]

22. Etzel, M.R. Manufacture and use of dairy protein fractions. J. Nutr. 2004, 134, 996S-1002S. [CrossRef]

23. Strom, M.B.; Haug, B.E.; Rekdal, O.; Skar, M.L.; Stensen, W.; Svendsen, J.S. Important structural features of 15-residue lactoferricin derivatives and methods for improvement of antimicrobial activity. Biochem. Cell Biol. 2002, 80, 65-74. [CrossRef]

24. Strom, M.B.; Rekdal, O.; Svendsen, J.S. The effects of charge and lipophilicity on the antibacterial activity of undecapeptides derived from bovine lactoferricin. J. Pept. Sci. 2002, 8, 36-43. [CrossRef]

25. Bellamy, W.; Takase, M.; Wakabayashi, H.; Kawase, K.; Tomita, M. Antibacterial spectrum of lactoferricin B, a potent bactericidal peptide derived from the N-terminal region of bovine lactoferrin. J. Appl. Bact. 1992, 73, 472-479. [CrossRef] [PubMed]

26. Ulvatne, H.; Haukland, H.H.; Olsvik, O.; Vorland, L.H. Lactoferricin B causes depolarization of the cytoplasmic membrane of Escherichia coli ATCC 25922 and fusion of negatively charged liposomes. FEBS Lett. 2001, 492, 62. [CrossRef]

27. Epand, R.M.; Vogel, H.J. Diversity of antimicrobial peptides and their mechanisms of action. Biochim. Biophys. Acta-Biomembr. 1999, 1462, 11-28. [CrossRef]

28. Kang, J.H.; Lee, M.K.; Kim, K.L.; Hahm, K.S. Structure-biological activity relationships of 11-residue highly basic peptide segment of bovine lactoferrin. Int. J. Pept. Protein Res. 1996, 48, 357-363. [CrossRef] [PubMed]

29. Haney, E.F.; Lau, F.; Vogel, H.J. Solution structures and model membrane interactions of lactoferrampin, an antimicrobial peptide derived from bovine lactoferrin. Biochim. Biophys. Acta-Biomembr. 2007, 1768, 2355-2364. [CrossRef]

30. Haney, E.F.; Nazmi, K.; Bolscher, J.G.M.; Vogel, H.J. Influence of specific amino acid side-chains on the antimicrobial activity and structure of bovine lactoferrampin. Biochem. Cell Biol. 2012, 90, 362-377. [CrossRef] [PubMed]

31. Vorland, L.H.; Ulvatne, H.; Andersen, J.; Haukland, H.H.; Rekdal, O.; Svendsen, J.S.; Gutteberg, T.J. Lactoferricin of bovine origin is more active than lactoferricins of human, murine and caprine origin. Scand. J. Infect. Dis. 1998, 30, 513-517.

32. Chapple, D.S.; Mason, D.J.; Joannou, C.L.; Odell, E.W.; Gant, V.; Evans, R.W. Structure-function relationship of antibacterial synthetic peptides homologous to a helical surface region on human lactoferrin against Escherichia coli serotype O111. Infect. Immun. 1998, 66, 2434-2440. [CrossRef]

33. Chaparro, S.C.V.; Salguero, J.T.V.; Baquero, D.A.M.; Perez, J.E.R. Effect of polyvalence on the antibacterial activity of a synthetic peptide derived from bovine lactoferricin against healthcare-Associated infectious pathogens. Biomed Res. Int. 2018, 2018, 5252891. [CrossRef] [PubMed]

34. Mendez, N.D.H.; Casanova, Y.V.; Chimbi, A.K.G.; Hernandez, E.; Castro, A.L.L.; Diaz, J.M.M.; Monroy, Z.J.R.; Castaneda, J.E.G. Synthetic peptides derived from bovine lactoferricin exhibit antimicrobial activity against E. coli ATCC 11775, S. maltophilia ATCC 13636 and S. enteritidis ATCC 13076. Molecules 2017, 22, 452. [CrossRef] [PubMed]

35. Chen, P.W.; Jheng, T.T.; Shyu, C.L.; Mao, F.C. Antimicrobial potential for the combination of bovine lactoferrin or its hydrolysate with lactoferrin-resistant probiotics against foodborne pathogens. J. Dairy Sci. 2013, 96, 1438-1446. [CrossRef] [PubMed]

36. Davey, H.M. Life, death, and in-between: Meanings and methods in microbiology. Appl. Environ. Microbiol. 2011, 77, 5571-5576. [CrossRef]

37. Berney, M.; Hammes, F.; Bosshard, F.; Weilenmann, H.U.; Egli, T. Assessment and interpretation of bacterial viability by using the LIVE/DEAD BacLight kit in combination with flow cytometry. Appl. Environ. Microbiol. 2007, 73, 3283-3290. [CrossRef]

38. Stocks, S.M. Mechanism and use of the commercially available viability stain, BacLight. Cytometry Part A 2004, 61, 189-195. [CrossRef] [PubMed]

39. Ulvatne, H.; Samuelsen, O.; Haukland, H.H.; Kramer, M.; Vorland, L.H. Lactoferricin B inhibits bacterial macromolecular synthesis in Escherichia coli and Bacillus subtilis. FEMS Microbiol. Lett. 2004, 237, 377-384. [CrossRef] 